\title{
Knowledge Attitude and Practice about Water-Pipe Smoking among Saudi Population
}

\section{Reema Fahad Abdulrahman Alnumair, Amal Hussain Mohammed Ali, Hussam Ahmed Mohammed Alghamdi}

Department of Medical Laboratories, College of Applied Medical Sciences, Qassim University, Qassim, Kingdom of Saudi Arabia Email: ama.ali@qu.edu.sa

How to cite this paper: Alnumair, R.F.A., Ali, A.H.M. and Alghamdi, H.A.M. (2020) Knowledge Attitude and Practice about Water-Pipe Smoking among Saudi Population. Journal of Biosciences and Medicines, 8, 58-72.

https://doi.org/10.4236/jbm.2020.83007

Received: January 28, 2020

Accepted: March 2, 2020

Published: March 5, 2020

Copyright $\odot 2020$ by author(s) and Scientific Research Publishing Inc. This work is licensed under the Creative Commons Attribution International License (CC BY 4.0).

http://creativecommons.org/licenses/by/4.0/

\begin{abstract}
Water pipe smoking has been practiced extensively for about 400 years. Water pipe smoking is common in the Saudi Arabia. Water-pipe smoking exposes smokers to high levels of tobacco and toxins. An observational and cross-sectional survey carried among 1170 participants to determine the knowledge, attitude, and practice about water-pipe smoking among Saudi population. Data was collected and obtained by the online questionnaire that has been created in Google form and then published in different social media platforms over a period from September 2019 to November 2019. The data were entered in Excel and analyzed in EpiInfo7 statistical software to get descriptive statistics. Results: About $70 \%$ were females and $30 \%$ male, $43 \%$ of them are university students with $83 \%$ in the age group of the $18-25$ high participants. Low knowledge of Carbon monoxide poisoning effects $=78 \%$, While $54 \%$ of the participants showed low knowledge about infectious disease transmitted by water-pipe. The Knowledge about water pipe contents and carbon monoxide poisoning was low. Further efforts will be necessary to increase the level of awareness among participants in Saudi Arabia regarding water pipe contents and carbon monoxide poisoning.
\end{abstract}

\section{Keywords}

Knowledge, Attitude, Practice, Water-Pipe, Smoking, Saudi

\section{Introduction}

Water-pipe smoking has been popular in Middle Eastern societies for several years, but now becoming more common around the globe [1]. Water-pipe is also known as Shisha, Hookah, Narghile, and Hubble bubble and many other names depending on the country. Many water-pipe smokers have a misconception, 
which is smoking the water-pipe is less harmful than cigarettes, because the smoke is filtered by the water before it is inhaled [2].

The prevalence of WP smoking was estimated that ranges from $6 \%$ to $34 \%$ among Middle East countries [3]. Any form of Smoking is a known health hazard being responsible for cardiovascular diseases, lung cancer, chronic bronchitis, and respiratory diseases. In Saudi Arabia, there is a new trend toward increased Shisha smoking [4]. The aim of this study is to measure the knowledge, attitude, and practice of water-pipe (Shisha) smoking among Saudi population and improve the awareness of population.

\subsection{Water Pipe}

Water-pipe has been used as a social activity in the Middle East and South Asia for more than 400 years [5]. But nowadays the practice has been increasing worldwide in the last few centuries [6]. The prevalence of water-pipe smoking among middle east adult is high [3]. Water-pipe is used to smoking tobacco. Tobacco causes more than 8 million deaths each year. Which is more than 7 million of these deaths is a result of direct tobacco use, while the rest of the deaths are result of non-smokers being exposed to second-hand smoke [6]. The main cause of these deaths is the exposure to smoke toxicants such as tobacco, nicotine, tar, carbon monoxide and heavy metals [7].

Several studies have shown that shisha smoking is practiced more frequently (either daily or once per week). Water pipes are passed from person to person and typical smoking sessions last between 45 and 50 minutes but may continue for several hours [8].

\subsection{Toxicological Profile}

Even though waterpipe has been present for many years, far fewer studies have examined its chemical constituents/air quality relative to cigarettes. The tobacco is the main source of smoke in both water pipe and cigarettes, water pipe users are exposed to many of the same toxic compounds as cigarette users but at dramatically higher levels, which causes produce worsened health effects in users [9]. Several toxicants have been found in waterpipe smoke including nicotine, carbon monoxide, furanic and phenolic compounds, aldehydes, particulate matter, heavy metals, and ammonia. The amounts of these toxicants may be different in waterpipe compared with cigarette smoke due to different heating process and charcoal combustion [10].

\subsection{Nicotine}

During an isolated water pipe use session in a clinical research lab, waterpipe smokers have a regular dose of $2.5 \mathrm{mg}$ of nicotine, which was equal to smoking 2 - 3 cigarettes [11]. In normal study of waterpipe smokers in water pipe bars, elevation of urine nicotine concentration around a 73 -fold was reported in water pipe smokers after one session [12]. The average plasma nicotine concentration 
within 24 hours after smoking waterpipe tobacco was equal to smoking 2 to 3 cigarettes [13].

\subsection{Carbon Monoxide Poisoning}

Carbon monoxide $(\mathrm{CO})$ is an odorless, tasteless, colorless, nonirritating gas formed by hydrocarbon combustion. Carbon monoxide will bind with hemoglobin to form carboxyhemoglobin $(\mathrm{COHb})$ in the blood. The atmospheric concentration of CO is generally below 0.001 percent. CO's affinity for hemoglobin is more than 243 times greater than that of oxygen [14]. This affinity prevents oxygen from binding to hemoglobin, which leads to hypoxemia and subsequent tissue hypoxia. CO can also precipitate an inflammatory cascade that results in CNS lipid peroxidation and delayed neurologic sequelae [15].

\subsection{Health Effects Associated with Water Pipe Smoking}

Water-pipe smoking is associated with a variety of adverse health outcomes such as heart disease, cancer, and respiratory illness, these are developed with a long term period. While the short term period adverse health outcome such as Carbon monoxide poisoning. Other adverse health includes the transmission of infectious diseases, such as tuberculosis, owing to the sharing of the water-pipe hose, a common practice in social gatherings [16].

\subsection{Effects on the Respiratory System}

\subsubsection{CO Toxicity}

WPS acutely leads to inhalation $\mathrm{CO}$ and increased carboxyhemoglobin $(\mathrm{COHb})$ or exhaled $\mathrm{CO}$ when compared to cigarette smokers and non-smokers. $\mathrm{COHb}$ affects the transportation of oxygen to various organs. $\mathrm{CO}$ poisoning can be presented with variable signs and symptoms. These are headache, visual disturbances, vomiting, confusion, ataxia, dyspnea, tachypnea, seizure, ECG changes, dysrhythmias, syncope, retinal hemorrhage, chest pain, bullous skin lesions and focal neurologic deficit [17].

\subsubsection{Case Studies and Reports}

There were four cases were reported in France, Singapore, and Turkey. The case happens in Saudi Arabia, show the carboxyhemoglobin level $(\mathrm{COHb})$ was $30 \%$, and the case reported in France, shows the carboxyhemoglobin level ( $\mathrm{COHb}$ ) was $20.8 \%$, and Singapore case was $27.8 \%$, and the last two cases in Turkey shows the carboxyhemoglobin level ( $\mathrm{COHb})$ was $28.7 \%$ and $31.1 \%$ [18], There was a case report of CO poisoning in Italy (2011), A female 16 years old smoked tobacco by water pipe for approximately 3 hours, the laboratory analysis of the blood gas, the carboxyhemoglobin level ( $\mathrm{COHb}$ ) was $24 \%$ (normal $0 \%-1.5 \%$ ) and which is above the normal range [19].

A study showed average significant decrease in oxygen saturation by $0.39 \%$ after a 30 min WPS session [20]. Chronic bronchitis increases the risk of infections and lung cancer; it may also progress to and constitute a part of chronic 
obstructive pulmonary disease (COPD) [21]. In N. Layoun et al. study, it shows that function of pulmonary and cardiovascular systems was observed to be affected by duration of smoking, age at first WP and quantity of smoking [22]. In M. H. Boskabady et al. study, the water pipe smokers have significantly more wheezing, chest tightness, coughing and sputum production compared with nonsmokers. Also, other studies show water pipe smokers had significantly higher severity and prevalence of respiratory symptoms compared to nonsmokers [23].

\subsection{Effects on the Cardiovascular System}

\section{High Heart Rate (Tachycardia)}

Acute effects of conventional smoking, such as elevated blood pressure, vascular resistance, and heart rate, it's known for 10 years [24]. In a cohort study, Heart rate elevation that exceeds $50 \mathrm{bpm}$ in $6.4 \%$ of participants and reaches more than $200 \mathrm{bpm}$ in $3.6 \%$ of participants after 30-min of shisha smoking session [20]. A study showed that changes in the cardiovascular central and peripheral components occur directly after shisha smoking and include high in HR, blood pressure, and after occlusion vascular resistance, while after occlusion blood flow and outflow were reduced [25].

In Selim et al. study, Smokers of both shisha and cigarettes had significantly higher systolic blood pressure and heart rate than exclusively cigarette smokers, shisha smokers, or non-smokers [26]. Acute use of shisha also stimulates changes in the peripheral vascular system in a similar way to cigarette smoking, such that it increased vascular resistance and reduced post occlusion blood flow [27].

In Numair KA et al. study, it was observed after shisha smoking that a mean increase in systolic and diastolic blood pressure and heart rate of shisha smokers. in the same study, they reported that serum concentration of HDL, Apo A in shisha smokers were significantly lower than nonsmokers. However, LDL-cholesterol, Apo B and triglycerides were significantly higher in smokers [28]. Actually, shisha smokers with more than 40 years had three times more risk of having severe stenosis than non-smokers [29]. Shisha smoking was associated with severe coronary artery disease, which was dependent on the duration/frequency of shisha smoking [30].

\subsection{Association of WPS with Cancer}

In Koul et al. study shows, there was a positive association between the severity of smoking and risk of developing lung cancer [31]. Also in Aoun et al. study, they said the main risk factors of lung cancer among Lebanese women are use of heating fuel and cigarette smoking [32]. Pancreatic cancer is a rapidly fatal disease; it's associated with tobacco smoking [33]. In Hosseini $\mathrm{M}$ et al. study, he reports that shisha smoking is one of the risk factors for prostate cancer [34].

\subsection{Infectious Disease}

It was rated that the practice of sharing a water-pipe mouth piece shows a se- 
rious risk of transmission of communicable diseases including Hepatitis and Tuberculosis [35]. The water pipe and the water inside the Shisha bowl can become an abode to the bacteria such as Mycobacterium tuberculosis; which leads to transmission the TB. It happens when sharing a pipe with someone with pulmonary TB, which leads to a great risk of TB transmission [36].

\section{Studies}

In Taha AZ et al. study, it's shown that the prevalence of shisha smoking among male medical students in Saudi Arabia was 8.6\%. A quite similar finding has been reported by Almutairi (2004) who found that among university students in Riyadh $7.3 \%$ of the study participants were shisha smokers [37]. In Al-Naggar and Bobryshev study, the finding result about shisha content was $75 \%$ of the participants think that shisha contains nicotine, and $79 \%$ of the participants think that shisha contains carbon monoxide, $68 \%$ of the participants think that shisha contains tar [38]. In Al-Naggar and Bobryshev study, $67.7 \%$ of the participants don't think that water in shisha filtering toxins, while $32.3 \%$ of the participants think that water in shisha filtering toxins [38].

In Taha AZ et al. study, it's shown $70 \%$ of participants like to smoking shisha at Cafes or restaurants, while $29 \%$ of participants like to smoking shisha at open places, $6 \%$ of participants like to smoking shisha at home, $1 \%$ of participants like to smoking shisha at sports clubs [37]. In Amin et al. study, it shows $50 \%$ of the participants think that Shisha smoking is harmful compared to cigarettes [39].

In Nazeer Khan et al. study when asked about infectious disease transmitted by shisha, $29.8 \%$ of the participants choose Tuberculosis, while $18.3 \%$ of the participants choose Hepatitis, $11.6 \%$ of the participants choose Herpes, $8.5 \%$ of the participants choose None [40]. In Amin et al. study, it shows 30\% of the participants were smoking shisha every two weeks, $24 \%$ smoking shisha weekly, $23 \%$ smoking shisha monthly, 21\% smoking shisha daily [39].

\section{Research Objectives}

\subsection{General Objectives}

To study the Knowledge, attitude and practice about water-pipe (Shisha) smoking among Saudi population.

\subsection{Specific Objectives}

1) To select the study subjects that include all Saudi males and females who are 18 years old and above.

2) To prepare a self-administered questionnaire that will be composed of End-closed answer that will aim to catch the knowledge of the study subjects regarding the study objective.

3) To publish the questionnaire online to the study subjects by the use of Google Forms and distributing the URL of this questionnaire across multiple 
multi-media platforms (WhatsApp, Twitter, Telegram, Snapchat and Instagram).

4) To collect the data gathered from the questionnaire in the form of Excel Sheets for each of the study subjects' answers.

5) To measure the knowledge about water-pipe (Shisha) smoking among Saudi population.

6) To assess attitude towards water-pipe (Shisha) smoking among Saudi population.

7) To evaluate the practice of water-pipe (Shisha) smoking among Saudi population.

8) To estimate the associations between the knowledge, attitude, and the practice about water-pipe (Shisha) Smoking among Saudi population.

\section{Methodology}

\subsection{Study Design}

The design of this study was an observational, cross-sectional study on the data obtained from the online self-administered questionnaire about the knowledge, attitude, and practice about water-pipe (Shisha) smoking. Participants of this study were both males and females who are 18 years old and above in Saudi Arabia. The study was conducted from September 2019 to November 2019.

\subsection{Conceptual Model of the Study}

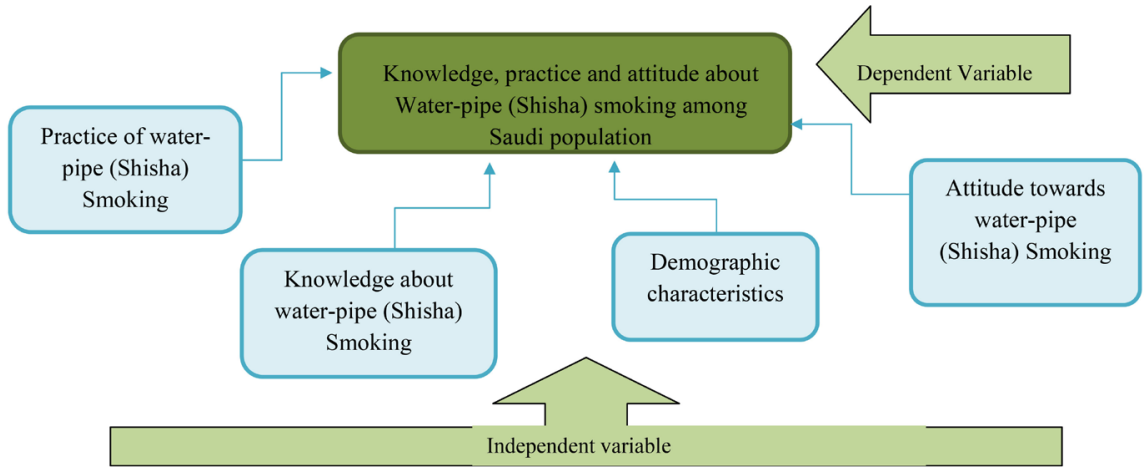

\subsection{Study Sample}

This study sample was a group of Saudi males and females who were 18 years old and above. This group of people who were randomly selected with size 1170 people.

\subsubsection{Inclusion Criteria}

- Saudi female and male participants.

- 18 years old and above participants.

- agreed to participate.

\subsubsection{Exclusion Criteria}

- non Saudi female and male participants.

- under 18 years old participants. 
- declined to participate.

\section{Data Collection}

Data was collected and obtained by the online questionnaire that has been created in google form and then published in different social media platforms (Twitter, Telegram, WhatsApp, Snapchat and Instagram). Participants filled an Arabic version of the online questionnaire which eased the understanding process for non-English speakers. The questionnaire was divided into 4 parts to cover the aim of the study, one part was for demographic characteristics, another part was for the knowledge about water-pipe (Shisha) smoking, a part for the attitude towards water-pipe (Shisha) smoking, and lastly a part about the practice of water-pipe (Shisha) smoking. Along with an informed consent and an explanation about the study objectives, the participants answered some end-closed MCQs, Multiple Choice Questions, in the span of 10 - 15 minutes.

\section{Data Analysis Plan}

Collected data will be entered in Microsoft Excel 2016 and then analyzed by EPI INFO 7 to get descriptive statistics with mean, proportion, percent and frequency distribution. The results will be interpreted in Microsoft Word 2016 in the form of tables and graphs.

\section{Ethical Considerations}

Ethical approval for this study will be obtained from the Department Research Review Committee, at the College of Applied Medical Sciences at Qaseem University. An informed consent will be given to the participants before they fill the questionnaire, as well as providing an explanation with the study objectives. All the data collected in this study will be kept confidential and used for research purposes only.

\section{Results}

From Table 1, the highest participants regarding the age criteria were in 18 - 25 years old (83\%), and there were more females (70\%), while university students were the most in education criteria (43\%), and people who have $<5000$ SAR income were the most (75\%), and there were more people from middle region (Qassim \& Riyadh) with percentage (43\%).

As Figure 1 shows, $77 \%$ of participants that not smoking waterpipe, while $15 \%$ smoking waterpipe, $8 \%$ were smoking in the previous.

As Figure 2 shows, $81 \%$ of participants that smoking waterpipe daily, while $32 \%$ smoking monthly, $26 \%$ were smoking weekly.

As Figure 3 shows, 39\% of participants that most like to smoking at Shisha bar (café), while 29\% like smoking at Home, 29\% like to smoking at Other places, $3 \%$ like to smoking at Restaurants.

Figure 4 depicts that most, $58 \%$ of participants don't believe that shisha is less 
Table 1. Description of demographic characteristics of the study sample.

\begin{tabular}{|c|c|c|}
\hline \multicolumn{2}{|c|}{ DEMOGRAPHIC CHARACTERISTICS } & \multirow{2}{*}{$\begin{array}{c}\text { FREQUENCY (\%) } \\
\text { n }=100 \\
969(83 \%)\end{array}$} \\
\hline Age: & $18-25$ & \\
\hline & $26-35$ & $155(10 \%)$ \\
\hline & $36-45$ & $40(4 \%)$ \\
\hline & $46-55$ & $19(1 \%)$ \\
\hline & 55 or more & $27(2 \%)$ \\
\hline \multirow[t]{2}{*}{ Gender: } & Female & $817(70 \%)$ \\
\hline & Male & $353(30 \%)$ \\
\hline \multirow[t]{6}{*}{ Education: } & High school & $372(31 \%)$ \\
\hline & University & $503(43 \%)$ \\
\hline & Diploma & $56(4 \%)$ \\
\hline & Bachelor & $205(18 \%)$ \\
\hline & Master or $\mathrm{PhD}$ & $32(3 \%)$ \\
\hline & Non-educated & $2(1 \%)$ \\
\hline \multirow[t]{4}{*}{ Income: } & $<5000$ SAR & $878(75 \%)$ \\
\hline & $5000-10,000$ SAR & $135(11 \%)$ \\
\hline & $10,000-15,000 \mathrm{SAR}$ & $79(7 \%)$ \\
\hline & $>15,000 \mathrm{SAR}$ & $78(7 \%)$ \\
\hline \multirow[t]{5}{*}{ Location: } & Middle region & $506(43 \%)$ \\
\hline & East region & $130(11 \%)$ \\
\hline & West region & $250(21 \%)$ \\
\hline & South region & $192(17 \%)$ \\
\hline & North region & $92(8 \%)$ \\
\hline
\end{tabular}

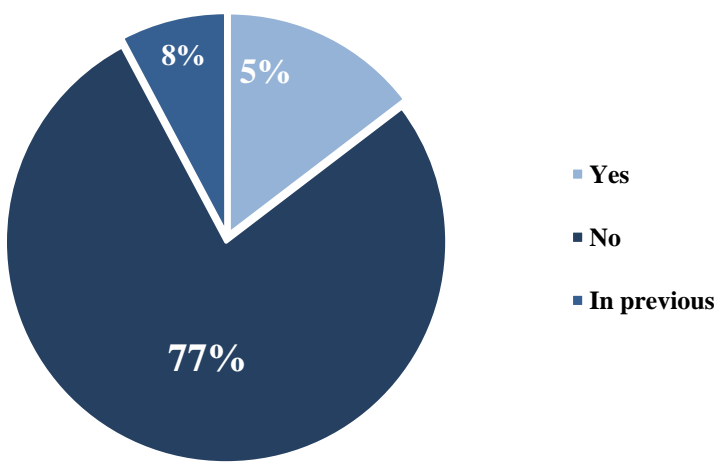

Figure 1. Description of smoking waterpipe.

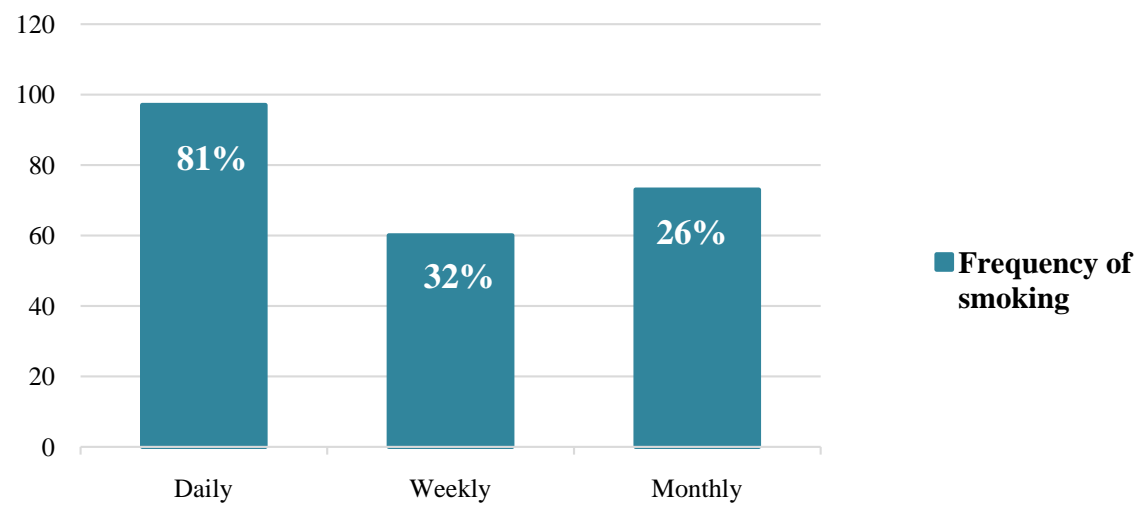

Figure 2. Description of the frequency of smoking waterpipe. 


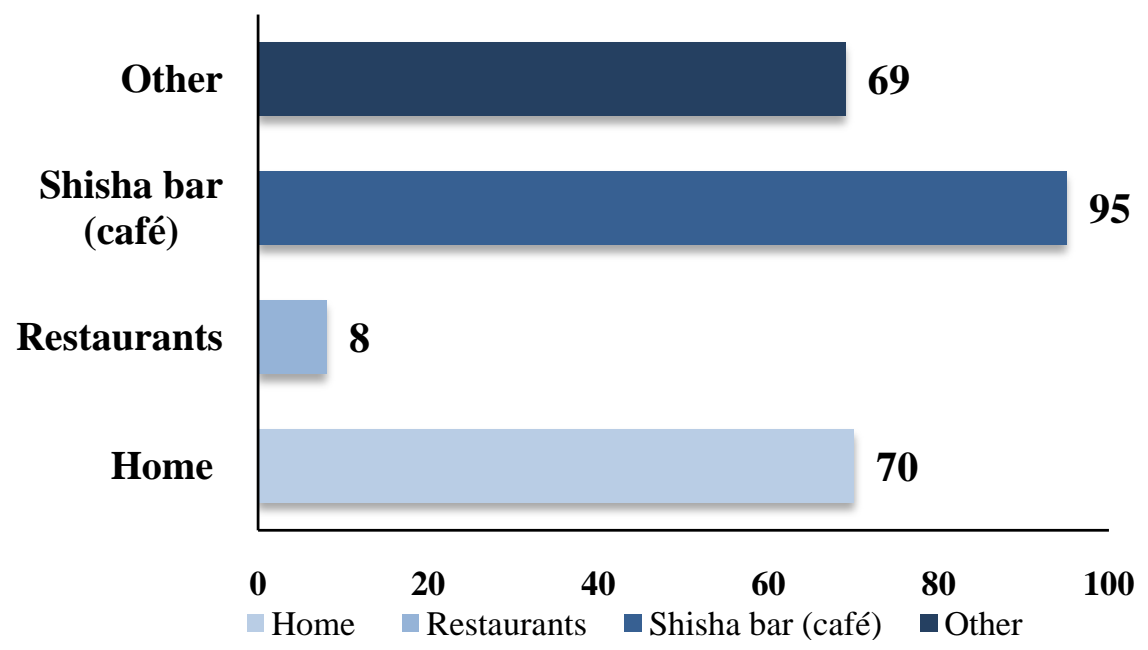

Figure 3. Description of places for smoking waterpipe.

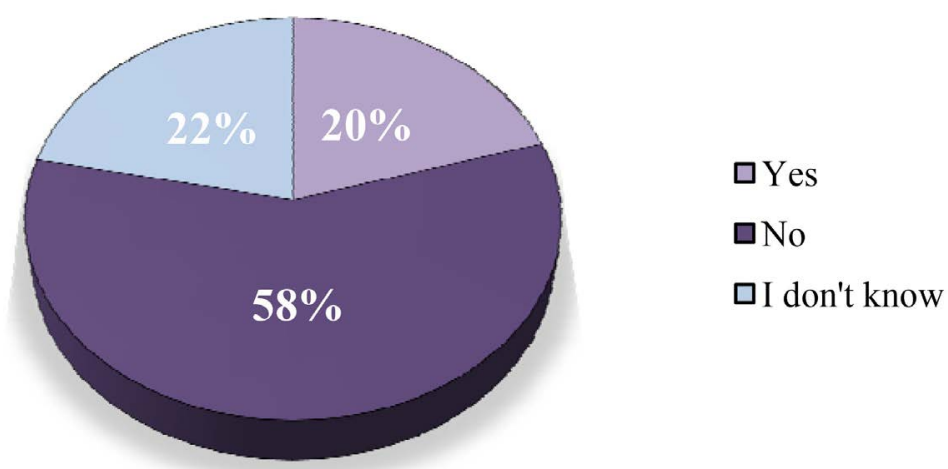

Figure 4. Description of knowledge about that shisha is less harmful than cigarettes.

harmful than cigarettes, and $20 \%$ believe that shisha is less harmful than cigarettes, while $22 \%$ didn't know.

The chart in Figure 5 shows that the most, $78 \%$ of participant didn't know about carbon monoxide poisoning, while $22 \%$ know about it.

As a bar chart in Figure 6 shows that 43\% of participants didn't know about the shisha contains. While $38 \%$ of participants think that contain all, $8 \%$ of them think that only contain nicotine. $6 \%$ think it only contains tobacco, while $5 \%$ think that contain carbon monoxide.

As pie chart in Figure 7 shows that the most, 54\% of participant didn't know about infectious disease transmitted by shisha, while $27 \%$ choose hepatitis, and $13 \%$ choose tuberculosis, $6 \%$ choose herpes.

The chart in Figure 8 shows that the most, $68 \%$ of participant think that water not filter the toxin, while $31 \%$ didn't know, $1 \%$ think that water filter the toxin.

\section{Discussion}

In Taha et al. study, it's shown that the prevalence of shisha smoking among male medical students in Saudi Arabia was 8.6\%. A quite similar finding has been reported by Almutairi (2004) who found that among university students in 


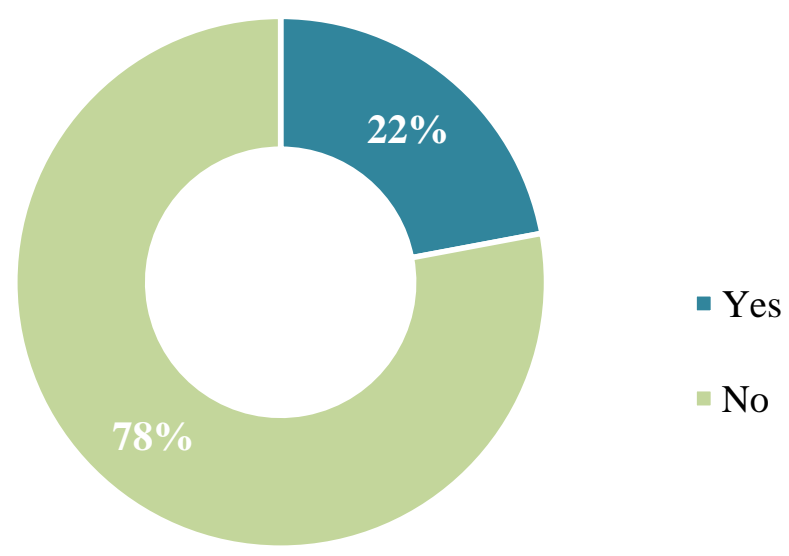

Figure 5. Description of knowledge about carbon monoxide poisoning.

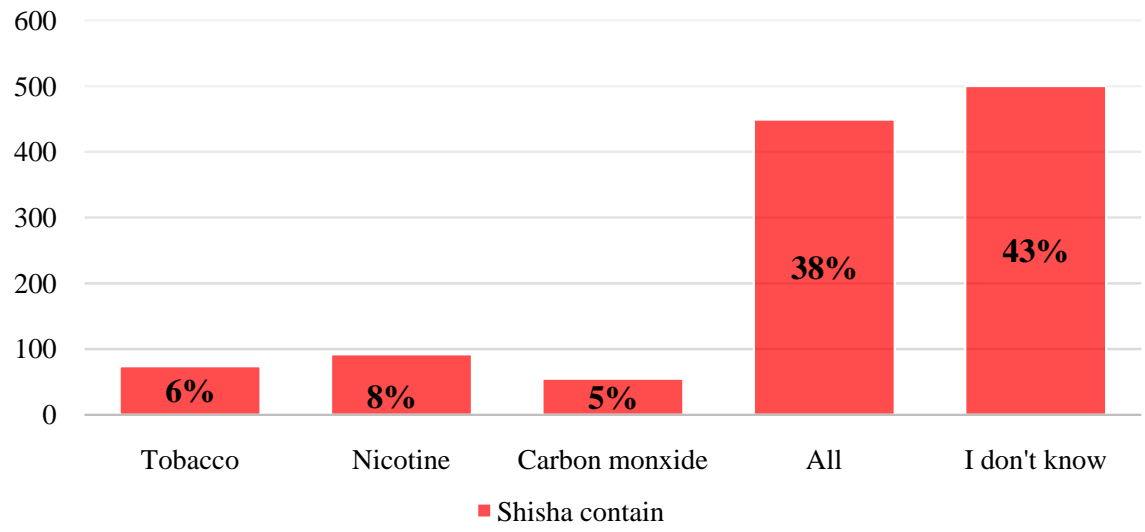

Figure 6. Description of knowledge about shisha contents.

- Hepatitis $\quad$ Tuberculosis $\quad$ Herpes $\quad$ I don't know

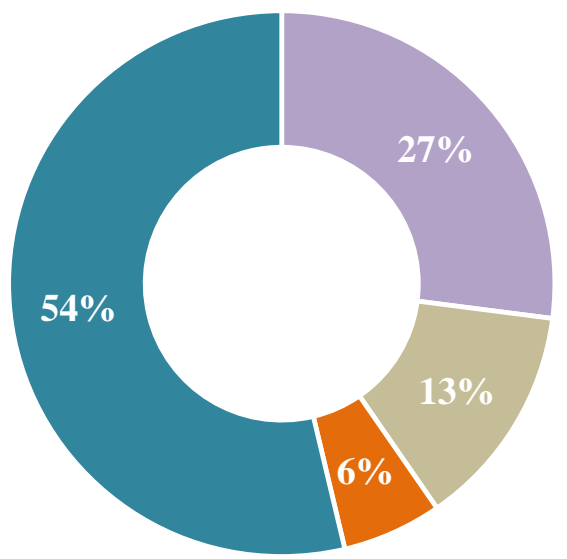

Figure 7. Description of knowledge about infectious diseases transmitted by shisha.

Riyadh $7.3 \%$ of the study participants were shisha smokers [37]. In our study, we found the total prevalence of shisha smoking was about $15 \%$, with $26 \%$ male and 9.6\% female, which can be considered as relatively high when compared with Taha and Almutairi studies. 


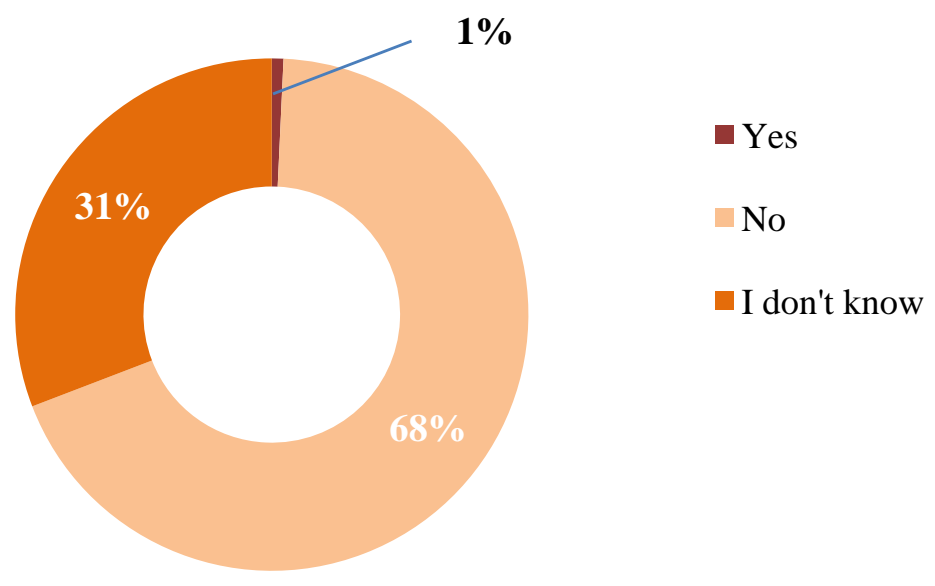

Figure 8. Description of shisha water effect on toxin.

In Attia Z. Taha, et al. study, it's shown $70 \%$ of participants like to smoking shisha at Cafes or restaurants, while $29 \%$ of participants like to smoking shisha at open places, $6 \%$ of participants like to smoking shisha at home, $1 \%$ of participants like to smoking shisha at sports clubs [37]. This result was similar to our study, 39\% of participants like to smoking shisha at shisha bar (Cafes), while $29 \%$ of participants like to smoking shisha at home, $29 \%$ of participants like to smoking shisha at other places, and 3\% like to smoking shisha at restaurants.

In Al-Naggar and Bobryshev study, the finding result about knowledge shisha content was $34 \%$ of the participants think that shisha contains nicotine, and 36\% of the participants think that shisha contains carbon monoxide, $30 \%$ of the participants think that shisha contains tar [38]. In our study shown, $43 \%$ of the participants didn't know about the shisha content, while $38 \%$ choose that shisha contains all of tobacco, nicotine and $\mathrm{CO}, 8 \%$ choose only nicotine, $6 \%$ choose only tobacco, $5 \%$ choose only CO. Unfortunately, most of the participants show a poor knowledge.

In Al-Naggar and Bobryshev study, $67.7 \%$ of the participants don't think that water in shisha filtering toxins, while $32.3 \%$ of the participants think that water in shisha filtering toxins [38]. We agree with Al-Naggar and Bobryshev study, $68 \%$ of the participants don't think that water in shisha filtering toxins, while $31 \%$ of the participants didn't know, $1 \%$ of the participants think that water in shisha filtering toxins. Which fortunately is considered as good knowledge of the participants.

In Amin et al. study, it shows $50 \%$ of the participants think that Shisha smoking is harmful compared to cigarettes [39]. According to our study, 58\% of the participants think it's not less dangerous cigarettes, while $20 \%$ of the participants think it's less dangerous than cigarettes, $22 \%$ of the participants didn't know.

In Amin et al. study, it shows $30 \%$ of the participants were smoking shisha every two weeks, $24 \%$ smoking shisha weekly, $23 \%$ smoking shisha monthly, $21 \%$ smoking shisha daily [39]. In this study, it shows $81 \%$ of the participants was smoking shisha daily, while $26 \%$ was smoking shisha monthly, $32 \%$ smoking 
shisha weekly.

In Nazeer Khan et al. study, when asked about infectious disease transmitted by shisha, $29.8 \%$ of the participants choose Tuberculosis, while $18.3 \%$ of the participants choose Hepatitis, $11.6 \%$ of the participants choose Herpes, $8.5 \%$ of the participants choose None [40]. In this study shown, 54\% of participant didn't know about infectious disease transmitted by shisha, while $27 \%$ choose hepatitis, and $13 \%$ choose tuberculosis, $6 \%$ choose herpes. Unfortunately, all the participants show poor knowledge regarding about infectious disease transmitted by shisha.

Many cases were reported about Carbon monoxide poisoning from waterpipe smoking: the first case was reported in Saudi Arabian in 2000, France, Singapore, Turkey and Italy (2011) [18]. Based on these cases we asked our participants about the knowledge of Carbon monoxide poising and we found $78 \%$ of the participants show poor knowledge.

\section{Conclusion}

Most of the study samples were females (18 to 25 years old) university students from the middle region. Our study shows the prevalence of shisha smoking on our participants was low. The misconception that waterpipe is less harmful than cigarettes was not found in this study. More than $39 \%$ of waterpipe smokers used shisha bar (café) for smoking. However, they lacked comprehensive knowledge about the shisha contents and carbon monoxide poisoning. Also, they have poor knowledge about the infectious disease transmitted by waterpipe (shisha).

\section{Recommendations}

1) Future research should include large and varied sample populations about water pipe smoking.

2) Research studies could focus on carbon monoxide poisoning by water pipe smoking.

\section{Conflicts of Interest}

The authors declare no conflicts of interest regarding the publication of this paper.

\section{References}

[1] Cobb, C., Ward, K.D., Maziak, W., Shihadeh, A.L. and Eissenberg, T. (2010) Waterpipe Tobacco Smoking: An Emerging Health Crisis in the United States. American Journal of Health Behavior, 34, 275-285. https://doi.org/10.5993/AJHB.34.3.3

[2] Al Ghobain, M., Ahmed, A., Abdrabalnabi, Z., Mutairi, W. and Al Khathaami, A. (2018) Prevalence of and Attitudes to Waterpipe Smoking among Saudi Arabian Physicians. https://doi.org/10.26719/2018.24.3.277

[3] Bahri, A.A., Gosadi, I.M., Mahfouz, M.S., Albasheer, O.B., Mawkili, Y.H., Mawkili, H.A., Yaqoub, H.A., Alwan, A.K., Jawahy, M.A. and Jabbari, O.M. (2018) Waterpipe Smoking: Prevalence and Associated Factors among Jazan University Students, 
Kingdom of Saudi Arabia. International Journal of Community Medicine and Public Health, 5, 5008-5013. https://doi.org/10.18203/2394-6040.ijcmph20184725

[4] Taha, A.Z., Sabra, A.A., Al-Mustafa, Z.Z., Al-Awami, H.R., Al-Khalaf, M.A. and Al-Momen, M.M. (2010) Water Pipe (Shisha) Smoking among Male Students of Medical Colleges in the Eastern Region of Saudi Arabia. Annals of Saudi Medicine, 30, 222-226. https://doi.org/10.4103/0256-4947.62838

[5] Moon, K.A., Magid, H., Torrey, C., Rule, A.M., Ferguson, J., Susan, J., et al. (2015) Secondhand Smoke in Waterpipe Tobacco Venues in Istanbul, Moscow, and Cairo. Environmental Research, 142, 568-574. https://doi.org/10.1016/j.envres.2015.08.012

[6] World Health Organization (2005) Waterpipe Tobacco Smoking: Health Effects, Research Needs and Recommended Actions by Regulators.

[7] Shafagoj, Y.A. and Mohammed, F.I. (2002) Levels of Maximum End-Expiratory Carbon Monoxide and Certain Cardiovascular Parameters Following Hubble-Bubble Smoking. Saudi Medical Journal, 23, 953-958.

[8] Maziak, W., Eissenberg, T., Rastam, S., et al. (2004) Beliefs and Attitudes Related to Narghile (Waterpipe) Smoking among University Students in Syria. Annals of Epidemiology, 14, 646-654. https://doi.org/10.1016/j.annepidem.2003.11.003

[9] Eissenberg, T. and Shihadeh, A. (2009) Waterpipe Tobacco and Cigarette Smoking: Direct Comparison of Toxicant Exposure. American Journal of Preventive Medicine, 37, 518-523. https://doi.org/10.1016/j.amepre.2009.07.014

[10] Qasim, H., et al. (2019) The Effects of Hookah/Waterpipe Smoking on General Health and the Cardiovascular System. Environmental Health and Preventive Medicine, 24, Article No. 58. https://doi.org/10.1186/s12199-019-0811-y

[11] Jacob, P., Abu Raddaha, A.H., Dempsey, D., Havel, C., Peng, M., Yu, L. and Benowitz, N.L. (2011) Nicotine, Carbon Monoxide, and Carcinogen Exposure after a Single Use of a Water Pipe. Cancer Epidemiology, Biomarkers \& Prevention, 20, 2345-2353. https://doi.org/10.1158/1055-9965.EPI-11-0545

[12] Momenabadi, V., Hossein Kaveh, M., Hashemi, S.Y. and Borhaninejad, V.R. (2016) Factors Affecting Hookah Smoking Trend in the Society: A Review Article. Addiction and Health, 8, 123-135.

[13] St Helen, G., Benowitz, N.L., Dains, K.M., Havel, C., Peng, M. and Jacob, P. (2014) Nicotine and Carcinogen Exposure after Water Pipe Smoking in Hookah Bars. Cancer Epidemiology, Biomarkers \& Prevention, 23, 1055-1066. https://doi.org/10.1158/1055-9965.EPI-13-0939

[14] Chakraborty, S., Balakotaiah, V. and Bidani, A. (2004) Diffusing Capacity Reexamined: Relative Roles of Diffusion and Chemical Reaction in Red Cell Uptake of $\mathrm{O}_{2}, \mathrm{CO}$, $\mathrm{CO}_{2}$, and NO. Journal of Applied Physiology, 97, 2284-2302. https://doi.org/10.1152/japplphysiol.00469.2004

[15] Martinasek, M.P., et al. (2014) Change in Carbon Monoxide Exposure among Waterpipe Bar Patrons. Nicotine \& Tobacco Research, 16, 1014-1019. https://doi.org/10.1093/ntr/ntu041

[16] Maziak, W., Ward, K.D., Afifi Soweid, R.A. and Eissenberg, T. (2004) Tobacco Smoking Using a Waterpipe: Are Emerging Strain in a Global Epidemic. Tobacco Control, 13, 327-333. https://doi.org/10.1136/tc.2004.008169

[17] Maloney, G. (2010) Carbon Monoxide. In: Tintinallis Emergency Medicine, 7th Edition, The McGraw Hill Companies, New York, 1410-1413.

[18] Lim, B.L., et al. (2009) Case of Carbon Monoxide Poisoning after Smoking Shisha. International Journal of Emergency Medicine, 2, 121-122. 
https://doi.org/10.1007/s12245-009-0097-8

[19] Fauci, G.L., et al. (2012) Carbon Monoxide Poisoning in Narghile (Water Pipe) Tobacco Smokers. CJEM, 14, 57-59. https://doi.org/10.2310/8000.2011.110431

[20] Al-Osaimi, A., Obaid, O., Al-Asfour, Y., et al. (2012) The Acute Effect of Shisha Smoking on Oxygen Saturation Level and Heart Rate. Medical Principles and Practice, 21, 588.

[21] Vestbo, J. (2004) Chronic Bronchitis: Should It Worry Us? Chronic Respiratory Disease, 1, 173-176. https://doi.org/10.1191/1479972304cd022rs

[22] Layoun, N., Saleh, N., Barbour, B., et al. (2014) Waterpipe Effects on Pulmonary Function and Cardiovascular Indices: A Comparison to Cigarette Smoking in Real Life Situation. Inhalation Toxicology, 26, 620-627. https://doi.org/10.3109/08958378.2014.945106

[23] Boskabady, M.H., Farhang, L., Mahmodinia, M., Boskabady, M. and Heydari, G.R. (2012) Comparison of Pulmonary Function and Respiratory Symptoms in Water Pipe and Cigarette Smokers. Respirology, 17, 950-956. https://doi.org/10.1111/j.1440-1843.2012.02194.X

[24] El-Nachef, W.N. and Hammond, S.K. (2008) Exhaled Carbon Monoxide with Waterpipe Use in US Students. JAMA, 299, 36-38. https://doi.org/10.1001/jama.2007.6

[25] Alomari, M.A., Khabour, O.F., Alzoubi, K.H., Shqair, D.M. and Eissenberg, T. (2014) Central and Peripheral Cardiovascular Changes Immediately after Waterpipe Smoking. Inhalation Toxicology, 26, 579-587. https://doi.org/10.3109/08958378.2014.936572

[26] Selim, G.M., et al. (2013) Effect of Shisha vs. Cigarette Smoking on Endothelial Function by Brachial Artery Duplex Ultrasonography: An Observational Study. The Anatolian Journal of Cardiology, 13, 759-765. https://doi.org/10.5152/akd.2013.4499

[27] Alomari, M.A., Khabour, O.F., Alzoubi, K.H., Shqair, D.M. and Stoner, L. (2015) Acute Vascular Effects of Waterpipe Smoking: Importance of Physical Activity and Fitness Status. Atherosclerosis, 240, 472-476. https://doi.org/10.1016/j.atherosclerosis.2015.02.047

[28] Al-Numair, K., Barber-Heidal, K., Al-Assaf, A. and El-Desoky, G. (2007) Water-Pipe (Shisha) Smoking Influences Total Antioxidant Capacity and Oxidative Stress of Healthy Saudi Males. The Journal of Food, Agriculture and Environment, 5,17 .

[29] Sibai, A.M., Tohme, R.A., Almedawar, M.M., Itani, T., Yassine, S.I., Nohra, E.A. and Isma'eel, H.A. (2014) Lifetime Cumulative Exposure to Waterpipe Smoking Is Associated with Coronary Artery Disease. Atherosclerosis, 234, 454-460.

https://doi.org/10.1016/j.atherosclerosis.2014.03.036

[30] Selim, G.M., Fouad, H. and Ezzat, S. (2013) Impact of Shisha Smoking on the Extent of Coronary Artery Disease in Patients Referred for Coronary Angiography. Anadolu Kardiyoloji Dergisi, 13, 647-654. https://doi.org/10.5152/akd.2013.191

[31] Koul, P.A., Hajni, M.R., Sheikh, M.A., et al. (2011) Hookah Smoking and Lung Cancer in the Kashmir Valley of the Indian Subcontinent. Asian Pacific Journal of Cancer Prevention, 12, 519-524.

[32] Aoun, J., Saleh, N., Waked, M., Salamé, J. and Salameh, P. (2013) Lung Cancer Correlates in Lebanese Adults: A Pilot Case-Control Study. Journal of Epidemiology and Global Health, 3, 235-244. https://doi.org/10.1016/j.jegh.2013.06.005

[33] Jarosz, M., Sekuła, W. and Rychlik, E. (2012) Influence of Diet and Tobacco Smok- 
ing on Pancreatic Cancer Incidence in Poland in 1960-2008. Gastroenterology Research and Practice, 2012, Article ID: 682156. https://doi.org/10.1155/2012/682156

[34] Hosseini, M., SeyedAlinaghi, S., Mahmoudi, M. and McFarland, W. (2010) A Case-Control Study of Risk Factors for Prostate Cancer in Iran. Acta Medica Iranica, 48, 61-66.

[35] Chaouachi, K.J. (2006) A Critique of the WHO TobReg's "Advisory Note" Report Entitled: Waterpipe Tobacco Smoking: Health Effects, Research Needs and Recommended Actions by Regulators. Journal of Negative Results in BioMedicine, 5, Article No. 17. https://doi.org/10.1186/1477-5751-5-17

[36] Chandir, S., Hussain, H., Salahuddin, N., Amir, M., Ali, F., Lotia, I. and Khan, A.J. (2010) Extrapulmonary Tuberculosis: A Retrospective Review of 194 Cases at a Tertiary Care Hospital in Karachi, Pakistan. Journal of Pakistan Medical Association, 60, 105-109.

[37] Taha, A.Z., Sabra, A.A., Al-Mustafa, Z.Z., Al-Awami, H.R., Al-Khalaf, M.A. and Al-Momen, M.M. (2010) Water Pipe (Shisha) Smoking among Male Students of Medical Colleges in the Eastern Region of Saudi Arabia. Annals of Saudi Medicine, 30, 222. https://doi.org/10.4103/0256-4947.62838

[38] Al-Naggar, R.A. and Bobryshev, Y.V. (2012) Shisha Smoking and Associated Factors among Medical Students in Malaysia. Asian Pacific Journal of Cancer Prevention, 13, 5627-5632. https://doi.org/10.7314/APJCP.2012.13.11.5627

[39] Amin, T.T., et al. (2011) Predictors of Waterpipe Smoking among Secondary School Adolescents in Al Hassa, Saudi Arabia. International Journal of Behavioral Medicine, 19, 324-335. https://doi.org/10.1007/s10865-011-9319-7

[40] Khan, N., et al. (2019) Prevalence, Knowledge, Attitude and Practice of Shisha Smoking among Medical and Dental Students of Karachi, Pakistan. Journal of the Dow University of Health Sciences, 2, 3-10. 